\title{
Understanding the link between obesity and headache- with focus on migraine and idiopathic intracranial hypertension
}

\author{
Connar Stanley James Westgate, Ida Marchen Egerod Israelsen, Rigmor Højland Jensen and Sajedeh Eftekhari ${ }^{*}$
}

\begin{abstract}
Background: Obesity confers adverse effects to every system in the body including the central nervous system. Obesity is associated with both migraine and idiopathic intracranial hypertension (IIH). The mechanisms underlying the association between obesity and these headache diseases remain unclear.

Methods: We conducted a narrative review of the evidence in both humans and rodents, for the putative mechanisms underlying the link between obesity, migraine and $\mathrm{IH}$.

Results: Truncal adiposity, a key feature of obesity, is associated with increased migraine morbidity and disability through increased headache severity, frequency and more severe cutaneous allodynia. Obesity may also increase intracranial pressure and could contribute to headache morbidity in migraine and be causative in $\mathrm{IH}$ headache. Weight loss can improve both migraine and IIH headache. Preclinical research highlights that obesity increases the sensitivity of the trigeminovascular system to noxious stimuli including inflammatory stimuli, but the underlying molecular mechanisms remain unelucidated.

Conclusions: This review highlights that at the epidemiological and clinical level, obesity increases morbidity in migraine and IIH headache, where weight loss can improve headache morbidity. However, further research is required to understand the molecular underpinnings of obesity related headache in order to generate novel treatments.
\end{abstract}

\section{Introduction}

Obesity is a global health issue, affecting over half a billion individuals and is defined by the World Health Organisation as having a body mass index $(\mathrm{BMI})>30 \mathrm{~kg} / \mathrm{m}^{2}$. Obesity constitutes a large disease burden in terms of socioeconomic costs and patient morbidity[1]. This is a consequence of obesity being a precipitating factor in a myriad comorbidities including type 2 diabetes mellitus, cancer, hypertension and premature death[2, 3]. Underlying these comorbidities is biochemical and hormonal dysfunction driven by excess adiposity and low-level

*Correspondence: sajedeh.eftekhari@regionh.dk

Danish Headache Center, Department of Neurology, Rigshospitalet- Glostrup, Glostrup Research Institute, University of Copenhagen, Nordstjernevej 42 , 2600 Glostrup, Denmark

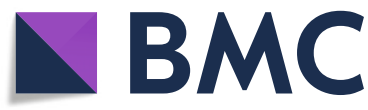

chronic inflammation. Given this systemic biochemical phenotype, obesity affects every aspect of the body including the nervous system .

Headache disorders such as migraine and the metabolic disease Idiopathic intracranial hypertension (IIH), have been associated with obesity. Migraine affects over a billion individuals, where migraine is associated with a high level of disability[4]. Epidemiologically, it is clear that migraine is over-represented in the obese population. However, the causes underlying this association have been considered controversial and under investigated. The vast majority of IIH patients are phenotypically obese females of reproductive age, where headache is the primary co-morbidity, thus IIH forms a case study of a disease of pure obesity and headache. However,

(c) The Author(s). 2021 Open Access This article is licensed under a Creative Commons Attribution 4.0 International License, which permits use, sharing, adaptation, distribution and reproduction in any medium or format, as long as you give appropriate credit to the original author(s) and the source, provide a link to the Creative Commons licence, and indicate if changes were made. The images or other third party material in this article are included in the article's Creative Commons licence, unless indicated otherwise in a credit line to the material. If material is not included in the article's Creative Commons licence and your intended use is not permitted by statutory regulation or exceeds the permitted use, you will need to obtain permission directly from the copyright holder. To view a copy of this licence, visit http://creativecommons.org/licenses/by/4.0/ The Creative Commons Public Domain Dedication waiver (http://creativecommons.org/publicdomain/zero/1.0/) applies to the data made available in this article, unless otherwise stated in a credit line to the data. 
although obesity and headache are a clear commonality, whether these are linked pathophysiologically is subject of debate. Although there is a link between obesity and these headache disorders, the underlying mechanisms driving the headache remain elusive.

In this narrative review, we have reviewed the clinical and epidemiological evidence for a link between obesity and the headache in migraine and IIH. We have explored the phenotypes, both clinical and molecular, to identify the links between obesity, migraine and IIH. Furthermore, the current review evaluates the preclinical evidence for alterations in headache like behaviour and the potential molecular underpinnings of these behavioural changes in rodents. Finally, the potential role of obesity on raised intracranial pressure (ICP) in the development of headache in migraine and IIH is discussed.

\section{Methods}

A narrative review was conducted where both clinical and preclinical evidence for a mechanistic link between obesity and the headache in migraine and IIH was evaluated. English language papers in both PubMed and Google Scholar were consulted for this review between its inception and September 2021, where both primary research and review articles were considered. Keywords utilised in this review included but were not limited to: ICP, headache, obesity, CGRP, migraine and IIH.

\section{Obesity: Epidemiology, pathogenesis and treatments}

Obesity is a disease on pandemic proportions, affecting over 650 million individuals worldwide, where the prevalence is highest in the developed world and is associated with low socio-economic status[5]. Obesity is associated with excess adiposity and increases the risk of developing serious comorbidities including type 2 diabetes mellitus, cancer, musculoskeletal diseases, cardiovascular diseases, metabolic syndrome, mental health issues and premature death $[2,3,6]$. However, obesity is a modifiable disease where BMI reduction confers improvement of the comorbid conditions and can be curative[6].

Obesity is a complex multifactorial disease where several components contribute to its pathogenesis. It is clear that obesity has a strong genetic component, where a genome wide association study identified that polymorphisms in multiple nervous system genes are associated with the development of raised BMI in European men and women[7]. Moreover, it has been demonstrated that polymorphisms associated with a lean phenotype also exist[8]. As such, obesity susceptibility can be described as a polygenic risk: where an accumulation of polymorphisms increases the risk of developing obesity. Additionally, environment plays a strong role in the development of obesity, where lifestyle, availability of calories and socio-economic status independently increase the risk of developing obesity in western society[9]. All of these components increase the risk of excess lipid accumulation in adipocytes, where excess adipocyte lipids cause a pro-inflammatory state that promotes the systemic manifestation of obesity[10].

There are various therapies for obesity, all of which focus on weight loss, which is the only disease modifying treatment for obesity. However, these therapies are often hampered by low efficacy and side effects where longterm remission can be difficult to maintain. Furthermore, these therapies are also multifunctional as they often treat co-morbidities of obesity[11]. Pharmacotherapy for obesity is becoming increasingly common, novel drugs are entering the market and is reviewed by Velazquez et al. here[11]. In brief, obesity pharmacotherapeutics aim to either directly modulate the processing of macronutrients or aim at altering gut-neuropeptides thus modulating systemic metabolism and feeding behaviour[11]. Weight loss can also be achieved surgically, where various forms of bariatric surgery are utilised[12]. Although these provide a mechanical alteration as to how food is processed postprandially, the primary mode of weight loss is mediated through changes in gut-neuropeptides[12]. This rebalancing of gut-neuropeptides alters feeding behaviour and the metabolic metabolism, thus facilitating weight loss[12].

Obesity is associated with insulin resistance, dyslipidaemia, an altered sexually dimorphic endocrine phenotype and increased circulating pro-inflammatory cytokines including IL-1 $\beta$, leptin and IL-6 and decreased circulating levels of anti-inflammatory cytokines such as adiponectin[13-15]. Consequently, obesity can be defined as both a metabolic disease and a state of chronic low-grade inflammation. Obesity is a disease with multimodal effects on physiology: adversely affecting the vasculature, where migraine pain may originate from the cerebral vasculature[16]. Furthermore, the chronic state of inflammation in obesity could be linked to the proposed role of neuroinflammation in migraine pathogenesis[16]. Given these, it is perhaps unsurprising that there is a link between migraine and obesity.

\section{Migraine: Epidemiology, features and treatments}

Migraine is a common disease, estimated to affect 1.04 billion individuals, where $18.9 \%$ of females and $9.8 \%$ of males have a migraine diagnosis[4]. Similarly to obesity, migraine is associated with a lower socioeconomic background[17]. Clinically, migraine is well defined by the ICHD-3 criteria[18]. Cutaneous allodynia, the perception of a painful stimulus that otherwise would not be painful, is present in $63.2 \%$ of patients with migraine. The severity of cutaneous allodynia is positively associated with the severity and frequency of migraine attacks and is a likely predictor of migraine 
chronification[19, 20]. However, migraine is not only a headache disorder, migraine patients experience premonitory and post monitory symptoms including tiredness and difficulty concentrating around the migraine attack, further contributing to disease morbidity[21]. Given the symptomology and commonality of migraine it comprises one of the largest disability burdens of any disease, second only to lower back pain[22].

Various therapeutics exist for the treatment of migraine, which either aim at treating migraine pain (abortive therapy) or preventing the development of a migraine attacks (preventative therapy). The primary abortive therapies for migraine are nonsteroidal anti-inflammatory drugs (NSAI DS), these are efficacious for some but are non-specific for migraine[23]. Triptans, $5-\mathrm{HT}_{1 \mathrm{~B} / \mathrm{D}}$ receptor agonists, are migraine specific abortive therapeutics[23]. Multiple nonspecific drugs are used to prevent migraine and fall into several classes including: antihypertensives, antidepressants, anticonvulsants and calcium channel blockers[23]. More recently, therapeutics that target the underlying migraine pain pathway have come to the market, monoclonal antibodies targeting calcitonin gene related peptide (CGRP) or its receptor with remarkable efficacy[23]. Treatments for migraine, whether abortive or preventative, are only symptomatic treatments as they do no treat the underlying pathology.

\section{Idiopathic intracranial hypertension: Epidemiology, features and treatments}

$\mathrm{IIH}$ is metabolic disease defined by raised intracranial pressure (ICP) and papilledema of unknown aetiology[24-28]. IIH is a rare disease, affecting 4.69 per 100,000 in the general population, where the incidence is increasing in line with the increasing incidence of obesity[29]. Indeed, the incidence of IIH is 20 per 100,000 in the obese population, with up to 64 per 100,000 in females[30]. There a several phenotypic presentations of IIH, however the most common is presenting in obese women of reproductive age. Thus, the disease associated with the female gender and obesity is the IIH that will be discussed in this review.

IIH patients present with a plethora of features outside of the diagnostic criteria that are seen in excess to that conferred by obesity. Cognitively, IIH patients have deficits in executive function and attention[31]. Perhaps linked to this, roughly half of IIH patients have obstructive sleep apnoea (OSA), where reduction in OSA following weight loss is associated with improved executive function and attention in IIH[32]. Headache is a predominant symptom in $\mathrm{IIH}$, where over $90 \%$ of patients experience headache. Headache represents the biggest cause of morbidity and disability after the visual components of the disease are resolved[33]. The headache phenotype in IIH has previously been reviewed in detail by Mollan et al.; where the headache phenotype in IIH is predominantly migrainous, thus leading to a state mimicking chronic migraine[34]. Given this evidence, we will consider migraine headache and IIH headache mechanistically synonymous in this review. Likely linked to the chronic headache in IIH, depression is a feature of IIH, perhaps unsurprising given the presence of chronic pain[35]. Indeed, IIH patients report that headache is the primary determinate in their quality of life and once resolved quality of life is much improved[33]. However, the other features of IIH are also reported to reduce their quality of life[36]. The mechanisms underlying the headache in IIH remain unelucidated and has been highlighted as a research focus[37].

Multiple treatments for IIH exist and depend on the severity of papilledema. In cases of fulminant IIH (vision at risk) neurosurgical CSF diversion is used to preserve vision[38]. Otherwise, IIH is medically managed primarily with acetazolamide and secondarily with topiramate[38]. These drugs are proposed to reduce ICP. However, a Cochrane review suggests that there is currently insufficient evidence to prescribe any drug for therapy in IIH[39]. Therapeutically, it has been demonstrated that weight loss improves the headache phenotype in IIH, in tandem with ICP reduction (see Table 1 for representative studies) [40]. However, IIH headache often persists after resolution of raised ICP and papilledema, this would suggest central sensitisation to pain stimuli $[34,41]$.

With regards to headache specific treatment, a recent open label study has demonstrated that the CGRP receptor monoclonal antibody erenumab reduces headache disability and morbidity in IIH patients who were already in ocular remission, i.e. with persistent headache[42]. Furthermore, erenumab has been demonstrated to treat headache in active IIH, while raised ICP and papilledema remain[43]. However, given the open label, non-controlled nature of these studies, further investigation is required. These studies suggest that other migraine specific therapeutics should be investigated for efficacy with IIH headache. Additionally, there is consensus that more research is required in understanding and treating headache in $\mathrm{IIH}[37]$.

\section{Epidemiology of migraine with obesity}

Given that obesity and migraine are ubiquitous in the population, it is inevitable that individuals will have concurrent obesity and migraine. Indeed the bulk of the literature suggests that there is an association between obesity and increased incidence of migraine[44]. A recent meta-analysis demonstrated that when covariates are taken into account, obesity confers a $21 \%$ increase in migraine diagnosis when compared to non-obese controls[45]. However, this increased risk is low compared 
Table 1 Weight loss treatments and effects on headache in migraine and IIH. Data presented depicts means before and after intervention. BMI = Body mass index, VAS = Visual analogue scale, VRS = Verbal rating scale, MIDAS = Migraine disability assessment

\begin{tabular}{|c|c|c|c|c|c|}
\hline \multicolumn{6}{|l|}{ Migraine } \\
\hline Migraine phenotype & Treatment & $\begin{array}{l}\text { Weight change } \\
\text { (BMI) }\end{array}$ & Headache frequency & $\begin{array}{l}\text { Headache severity/ medication } \\
\text { intake }\end{array}$ & Ref \\
\hline $\begin{array}{l}\text { Episodic migraine } \\
\text { w/out aura }\end{array}$ & $\begin{array}{l}\text { Ketogenic diet } 3 \text { months on } \\
\text { diet }\end{array}$ & 27.5 to 23.2 & $\begin{array}{l}\text { (n/month):5.1 to } 3.2(\mathrm{P}< \\
0.05)\end{array}$ & $\begin{array}{l}\text { Tablet intake (n/month): } 4.9 \text { to } \\
2.8(P<0.05)\end{array}$ & {$[52]$} \\
\hline $\begin{array}{l}\text { Episodic migraine } \\
\text { w/out aura }\end{array}$ & $\begin{array}{l}\text { Nutritionist assisted diet, } 3 \\
\text { months }\end{array}$ & 27.8 to 24.6 & $\begin{array}{l}\text { (n/month): } 6.3 \text { to } 4.2(\mathrm{P}< \\
0.05)\end{array}$ & $\begin{array}{l}\text { Tablet intake ( } \mathrm{n} / \text { month): } 5.9 \text { to } \\
3.8(\mathrm{P}<0.05)\end{array}$ & \\
\hline Migraine ICHD2 & Vegan diet 16 weeks & 26.9 to 25.5 & (n/week):2.1 to 1.7 & VAS: 6.0 to $3.6(P<0.0001)$ & [53] \\
\hline Migraine ICHD2 & $\begin{array}{l}\text { Placebo dietary supplements } \\
16 \text { week }\end{array}$ & 26.2 to 26.2 & (n/week):2.1 to 1.8 & VAS: 4.7 to 4.1 & \\
\hline Migraine w/out aura ICHD2 & $\begin{array}{l}\text { Gastric banding, } 6 \text { month } \\
\text { follow-up }\end{array}$ & 42.4 to 34.6 & $\begin{array}{l}\text { (n/month): } 6.0 \text { to } 1.0(P< \\
0.001)\end{array}$ & MIDAS: 21 to $4(P<0.001)$ & {$[54]$} \\
\hline \multicolumn{6}{|l|}{$\mathrm{IIH}$} \\
\hline $\begin{array}{l}\text { Phase of disease at study } \\
\text { entry }\end{array}$ & Treatment & $\begin{array}{l}\text { Weight change } \\
\text { (BMI) }\end{array}$ & Headache frequency & Headache severity & Ref \\
\hline$>3$ months after diagnosis & $\begin{array}{l}\text { Low calorie diet trial } \\
3 \text { months }\end{array}$ & 38.6 to 32.6 & $\begin{array}{l}\text { (Days/week): } 4.4 \text { to } 2.1 \\
(\mathrm{P}=0.011)\end{array}$ & VAS: 4.2 to $1.9(P=0.015)$ & [55] \\
\hline $\begin{array}{l}\text { Mean } 1 \text { year after diagnosis at } \\
\text { baseline }\end{array}$ & $\begin{array}{l}\text { Bariatric surgery } \\
1 \text { year after randomisation }\end{array}$ & 44.2 to 35.1 & $\begin{array}{l}\text { (Days/week): } 5.5 \text { to } 1.8 \\
(P<0.001)\end{array}$ & VRS: 5.0 to $3.2(P=0.002)$ & [40] \\
\hline $\begin{array}{l}\text { Mean } 1 \text { year after diagnosis at } \\
\text { baseline }\end{array}$ & $\begin{array}{l}\text { Community weight } \\
\text { management } \\
1 \text { year after randomisation }\end{array}$ & 43.7 to 43.1 & $\begin{array}{l}\text { (Days/week): } 5.6 \text { to } 4.1 \\
(P=0.007)\end{array}$ & VRS: 5.0 to $4.0(P=0.1)$ & \\
\hline Newly diagnosed & $\begin{array}{l}\text { Routine clinical care } 1 Y \\
\text { follow-up study }\end{array}$ & 35.5 to 31.8 & Daily 86-43 \% & VAS: 7.5 to 4.5 & [41] \\
\hline
\end{tabular}

to the cardinal comorbidities associated with obesity including type 2 diabetes mellitus $(574 \%)$ and hypertension $(84 \%)$ [3].

When assessing by age group, it is clear that obesity increases the risk of migraine for patients under 55 years old, particularly for women[46]. This increased incidence in early life is in keeping with the general migraine population and suggests an endocrine component to obesity associated migraine. Obesity effects migraine phenotype, whereby patients with concurrent migraine and obesity are more likely to have a chronic migraine (CM) diagnosis[47]. This suggests that obesity is a risk factor for migraine chronification [47]. Additionally, obesity is associated with a BMI dependent increase in migraine disability, suggesting that obesity increases severity of migraine attacks[48]. Linked to this, obesity has also been demonstrated to be associated with a higher attack frequency, where an apparent dose dependent relationship exists between BMI and headache days[49]. In the paediatric population higher BMI is also associated with increased severity, frequency and disability of migraine, however additional studies are required to confirm this single study[50].

Intuitively, if obesity contributes to the severity of migraine, then weight loss would confer an improvement of symptoms. Indeed, a recent meta-analysis highlights that weight loss, independent of intervention, reduces headache duration, frequency, severity and disability associated with migraine (see Table 1 for representative studies)[51]. This suggests that weight loss is a potential therapeutic strategy for migraine, given that the outcome was independent of starting BMI. Weight loss has also been demonstrated to reduce headache days in paediatric migraine[50]. However, given the low numbers in the weight loss studies, more extensive clinical studies are required in assess the efficacy of weight loss as a migraine treatment. Although weight loss has therapeutic benefits in migraine, weight loss is difficult to achieve and maintain, thus understanding the molecular underpinnings of obesity related migraine is vital in the development of novel therapeutics.

Together, the evidence highlights that obesity confers an increased risk of developing migraine, in particular increasing migraine morbidity. This increased morbidity could partially explain why obese patients are more likely to report migraine: more severe symptoms would necessitate clinical intervention rather than selfmanagement.

\section{Migraine pathophysiology and obesity}

The cause of primary migraine is still unknown, however it is considered to involve genetic factors, activation of the trigeminovascular system, changes in thalamic function and/or dysfunction of the brainstem and release of 
neuropeptides such as calcitonin gene-related peptide (CGRP)[16]. However, it is clear that in the majority of cases of migraine, it is a combination of these factors that leads to the onset of a migraine attack. Genetics, environment and biochemical factors play a cumulative role altering the threshold for a migraine attack.

Genetics play a large role in the susceptibility of developing migraine, perhaps up to $50 \%$ of the risk[23]. The vast majority of migraine it thought to be mediated by an accumulation of migraine promoting polymorphisms, i.e migraine susceptibility is a consequence of polygenic risk $[56,57]$. However, the polygenic risk is not determinative for migraine. Rather, it lowers an individual's threshold for migraine, meaning other factors that can precipitate a migraine have the opportunity to prevoke a migraine attack.

CGRP is a potent vasodilatory neuropeptide which also transmits nociceptive information and consists of two variants; $\alpha C G R P$ and $\beta C G R P$. $\alpha$ CGRP is predominantly expressed in the central nervous system and $\beta C G R P$ is primarily expressed in the enteric sensory system. CGRP has been demonstrated to have a significant role in migraine pathophysiology as clinical studies have shown increased levels of CGRP in serum, cerebrospinal fluid, and saliva of migraine patients[58-61]. In support of this, systemic infusion of CGRP can trigger a migraine headache in patients[62]. Therefore, targeting CGRP signalling with small molecule receptor antagonists or with monoclonal antibodies targeted to either the ligand or receptor, have been developed with clinical efficacy[63]. The CGRP receptor consists of the calcitonin receptorlike receptor (CLR) and receptor activity-modifying protein 1 (RAMP1)[64-66]. CGRP can also act and function via the amylin 1 receptor consisting of calcitonin receptor (CTR) and RAMP1, suggesting that CGRP can act at more than one receptor[67, 68]. CGRP and its receptors are widely distributed in the CNS, particularly at regions thought to be involved in migraine pathophysiology, including the trigeminal ganglion (TG), dura mater, brainstem and the cerebellum[69-74].

In the context of obesity, it has been shown that women with obesity had elevated plasma levels of CGRP compared to controls[75]. Preclinical studies have also demonstrated a link between obesity and CGRP. Zucker rats, a model of genetic obesity through hyperphagia related to a non-functioning leptin receptor, have elevated plasma levels of CGRP while pre-obese, although this was not assessed in obese rats[76]. In a specific $\alpha$ CGRP knockout $\left(\alpha \mathrm{CGRP}^{-/-}\right)$mouse model, it was demonstrated that these mice were protected from dietinduced obesity and maintained normal glycaemic control[77]. This suggests that CGRP has role in metabolic regulation, likely linked to CGRP receptor in the gut[77]. The effect of obesity on the trigeminovascular system has been investigated in rodents, where the basal release of CGRP from meningeal afferents was increased in diet-induced obese rats[78].

The pancreatic hormone amylin is a pro-satiety hormone and is released in the post-prandial state[79]. Amylin shares 25-50\% sequence homology with CGRP and is a well characterised agonist of the CGRP receptor. As with CGRP, levels of amylin are also elevated in obese individuals[79]. Amylin and its analogues are known to induce migraine attacks in patients with migraine[80]. As such, the dual increase of serum amylin and CGRP in obesity could contribute to the increased risk of migraine associated with obesity. Clinically, amylin analogues have been developed to treat type 1 and type 2 diabetes mellitus as well as obesity[81]. Given the capacity of amylin and its analogues to promote headache, the migraine history of a patient should be considered prior initiating amylin receptor agonist therapy to treat diabetes.

Another mechanism that may be involved in migraine is cortical spreading depression (CSD) [82, 83]. CSD consists of a spreading wave of depolarization associated with a reduction of cortical activity and has been related to migraine with aura. CSD in rodents can be evoked by various experimental triggers, and it is used as a model for migraine aura and for evaluating anti-migraine drugs [82, 84-86]. Obese Zucker rats have been demonstrated to have an increased number of CSDs, suggesting obesity affects cortical excitability [87]. Interestingly, in lean rats a CNS infusion of leptin increases the number of CSD's, linking the higher serum leptin levels in migraine with aura with the proposed increase of migraine with aura in obese females[87-89]. However other physiological changes in obesity may affect the qualities of CSD's, this requires further investigation.

These studies demonstrate that factors associated with migraine development, are increased in the context of obesity. Consequently, this provides biochemical evidence that obesity could contribute to an increased risk of developing and aggravating migraine.

\section{Endocrinology and body composition in migraine and IIH} Although it is apparent that obesity is associated with migraine and $\mathrm{IIH}$, the mechanisms underlying this remain unclear. Obesity has profound effects on human metabolism and endocrinology, where the distribution of adiposity dictates the level of metabolic and hormonal derangement $[90,91]$. More specifically, abdominal and visceral obesity is associated with more severe metabolic outcomes[90, 91].

Given this, it is curious that abdominal obesity was associated with a higher prevalence of migraine in both men and women below 50 years of age, although women are particularly affected $(\mathrm{OR}=1.26)[46]$. In addition, at a 
given BMI, migraine patients with cutaneous allodynia have greater visceral adiposity compared to migraine without cutaneous allodynia. This visceral adiposity present with cutaneous allodynia is associated with increased disability[92]. Assessing the capacity of weight loss to modify cutaneous allodynia in migraine patients would be important to allow additional strategies to manage this disabling feature of migraine. No differences in the pro-inflammatory cytokines TNF- $\alpha$ and IL- 6 were observed between cutaneous allodynia and noncutaneous allodynia patients, suggesting inflammation is not a factor underlying the cutaneous allodynia[92]. This highlights a need to further investigate the potential aetiology of the cutaneous allodynia observed with increased visceral adiposity. This link between visceral adiposity and cutaneous allodynia is curious as both cutaneous allodynia and obesity are risk factors for migraine chronification and disability[20,47]. Given that increased visceral adiposity is associated with migraine, it could be expected that migraine patients have an altered hormonal profile, as is observed in abdominal obesity. In the context of IIH, recent evidence suggests that these patients have increased abdominal obesity relative to matched obese controls and that this abdominal fat plays a key role for the development of IIH[26]. It is yet unknown if adiposity itself is associated with headache in IIH.

Several studies have assessed the link between migraine and insulin resistance, a key metabolic feature of obesity. They demonstrated a degree of insulin resistance among fasted migraine patients as measured by the homeostatic assessment model (HOMA) compared to BMI and aged matched controls[93-95]. However, there is disagreement as to whether a $\mathrm{CM}$ or episodic migraine (EM) diagnosis is more highly associated with insulin resistance relative to controls. When directly comparing $\mathrm{CM}$ and EM, CM patients were demonstrated to be more insulin resistant than EM patients[93, 94]. These data could suggest similarities in the molecular underpinnings of $\mathrm{CM}$ and insulin resistance. In all these studies the migraine and control population were matched for BMI and none of the groups fell in the obese BMI category, and there were no changes in fasting glucose and glucose tolerance tests. The increased insulin resistance in CM could be linked to the aforementioned increased risk of $\mathrm{CM}$ in obesity. However, to our knowledge no studies have assessed insulin resistance in patients with concurrent obesity and migraine vs. patients with obesity. Such studies would help to delineate whether the increased insulin resistance in migraine is associated with concomitant obesity or a consistent part of the pathology. This increased insulin resistance in migraine is consistent with the observations of increased abdominal adiposity in migraine. In IIH, there is a severe insulin resistance phenotype, greater than that conferred by obesity[26]. Again, this increased insulin resistance is in keeping with increased abdominal obesity for a given BMI.

The adipokine leptin, which is raised in obesity, has also been associated with migraine. A single study has demonstrated that migraine patients have a higher serum leptin level, when adjusted for age, sex and BMI[88]. When split into migraine with aura (MA) and without aura (MO), MA patients had raised serum leptin whereas $\mathrm{MO}$ did not have raised leptin [88]. This likely links to the proposed increased risk of MA in women with obesity, particularly because women with obesity have higher serum leptin relative to males with obesity $[89,96]$. Given the link between MA and CSD, the clinical findings of raised leptin in MA patients corroborate the pre-clinical finding that leptin experimentally alters CSDs and potentially provides a partial mechanism[87]. IIH patients have hyperleptinaemia in excess to that conferred by obesity[26]. However, in contrast to migraine where high leptin is associated with aura, there is currently little understanding about the frequency of aura in IIH patients. A single study reported $10 \%$ of $\mathrm{IIH}$ patients have aura, much lower than the $\sim 30 \%$ in the general migraine population[97].

The studies presented demonstrate that there are similarities between obesity, migraine and $\mathrm{IIH}$ at the biochemical and anthropomorphic level (Table 2). However, whether the similarities are coincidence or contributors to headache parthogenisis requires further

Table 2 Hormonal and anthropomorphic comparisons between obesity, migraine and IIH. Migraine with aura = MA, chronic migraine $=\mathrm{CM}$, cutaneous allodynia $=\mathrm{CA}$

\begin{tabular}{|c|c|c|c|}
\hline Hormone & Migraine & Obesity & $\mathrm{IIH}$ \\
\hline CGRP & Ictal $\uparrow[1]$ & $\uparrow[2]$ & Not investigated \\
\hline Amylin & Inter ictal $\uparrow[3]$ & $\uparrow[4]$ & Not investigated \\
\hline Leptin & $\mathrm{MA} \uparrow[5]$ & $\uparrow[6]$ & $\uparrow \uparrow[7]$ \\
\hline \multicolumn{4}{|l|}{ Hormone state } \\
\hline Insulin resistance & CM $\uparrow$ BMI Independent [8] & $\uparrow[9]$ & $\uparrow \uparrow[7]$ \\
\hline Central adiposity & $\uparrow C A[10]$ & $\uparrow$ body fat [9] & $\uparrow$ Central obesity [7] \\
\hline
\end{tabular}


investigation. The present studies do not compare the endocrine profile of obesity related migraine to obesity. Such studies could help identity key differences that point to pathogenic moieties.

\section{The link between obesity and migraine, in-vivo behavioural and functional evidence}

Several animal studies have explored the effects of obesity on migraine-like behaviour in mice, where photophobia and nocifensive behaviours have been assessed. It was demonstrated that both obese female and male mice develop a very modest basal photophobia that was accentuated by facial administration of capsaicin, a TRPV1 agonist and nociceptive[98, 99]. The degree of photophobia was weight dependent in high fat diet males, but not in female mice[98, 99]. This photophobic phenotype is replicated in genetically obese $o b / o b$ mice on a normal diet, whereas lean mice on a high fat diet did not exhibit this behaviour, suggesting that excess adiposity confers a photophobic phenotype rather than a high fat diet[98]. However, the basal photophobia studies required large numbers of mice $(n>40)$ indicating a small effect that may not be functionally relevant.

There is also a suggestion of facial thermal cutaneous allodynia in obese mice, where obese female mice develop a stronger allodynia[100]. Paradoxically $o b / o b$ mice show facial thermal cutaneous hypoalgesia, linking the presence of leptin to cephalic pain[101]. Although there is a suggestion of thermal cutaneous allodynia, there is currently no evidence of mechanical cutaneous allodynia in obese rodents. The capacity of obesity to modify mechanical cutaneous allodynia should be assessed given that mechanical cutaneous allodynia is readily treatable with migraine specific dugs in rodents[102]. The modest basal differences in behaviour that are modified by noxious stimuli suggest that excess adiposity increases the sensitivity of the rodent trigeminovascular system to noxious stimuli. Together, these data provide behavioural evidence that obesity potentiates migraine related nocifensive behaviour in rodents and thus provides preclinical evidence for the link between obesity and migraine.

\section{Functional alterations in the trigeminovascular system}

Given the evidence that obesity adversely alters nocifensive behaviours associated with migraine and sensitivity in the trigeminovascular system, one would expect to observe obesity associated functional disturbances in these structures that could underlie these behavioural differences.

Cultured TG neurons derived from obese mice had a stronger calcium response to capsaicin than those derived from non-obese mice, indicating increased sensitivity to a noxious stimulus via TRPV1 agonism[98].
Although the mechanism underlying this was not delineated, it is feasible that it could be mediated by obesity associated inflammation. Pro-inflammatory cytokines promote membrane translocation of TRPV1 in nociceptive neurons, although this has yet to be demonstrated in the context of the TG in obesity[103]. Additionally, the capacity of obesity to alter CGRP release in TG has not been assessed.

It has been shown that dura mater from obese, insulin resistant rats released more CGRP basally and when stimulated with TRPA1 and TRPV1 agonists acrolein and capsaicin in the half cranial model $[78,104]$. This corroborates the increased TRPV1 sensitivity of obese TG neurons to capsaicin, where in situ, TG neurons innervate the dura mater[98]. This increased response to noxious stimuli in the dura mater and TG may explain why capsaicin administration causes increased pain signalling, as indicated by increased activation in the external laminae of the trigeminal nucleus caudalis in obese mice, suggesting increased sensitivity to noxious stimuli [105].

Vasodilation in dural arteries is a proposed site for the origin of migraine pain[16]. Consequently, changes in sensitivity to vasodilators may alter the likeliness of developing a migraine. In obese rats, TRPA1 and TRPV1 agonists potentiate middle meningeal artery (MMA) blood flow, thus cause a vasodilation to a greater magnitude compared to control rats[78, 104]. Interestingly histamine and CGRP responses to MMA blood flow were comparable between obese and control rats, suggesting that the mechanism behind the difference is in part neuronal, rather than vascular. However, given the increase in basal dural CGRP release, dural arteries could become resistant to CGRPs vasodilatory functions. Together these studies suggest that the dural afferents of obese rats are more sensitive to noxious stimuli, thus promote a reflex associated with migraine.

Together this body of evidence suggests that obesity increases the sensitivity of the trigeminovascular system to noxious stimuli, supporting the capsaicin induced behavioural abnormalities seen in obese mice. However, the present body of work does not pinpoint the molecular origin of these trigeminovascular disturbances in obesity and thus the increased noicfensive behaviour (Fig. 1). Additionally, the majority of work assessing the effects of obesity on migraine-like behaviour in rodents has been done in male rodents. Given that females make up the majority of migraine patients, assessing the effects of obesity on migraine-like behaviour in female rodents is essential.

\section{Obesity related factors and inflammation}

Obesity is a disease of chronic systemic and tissue level inflammation and endocrine dysfunction; adipose tissue, the liver and pancreatic islets demonstrate obesity 


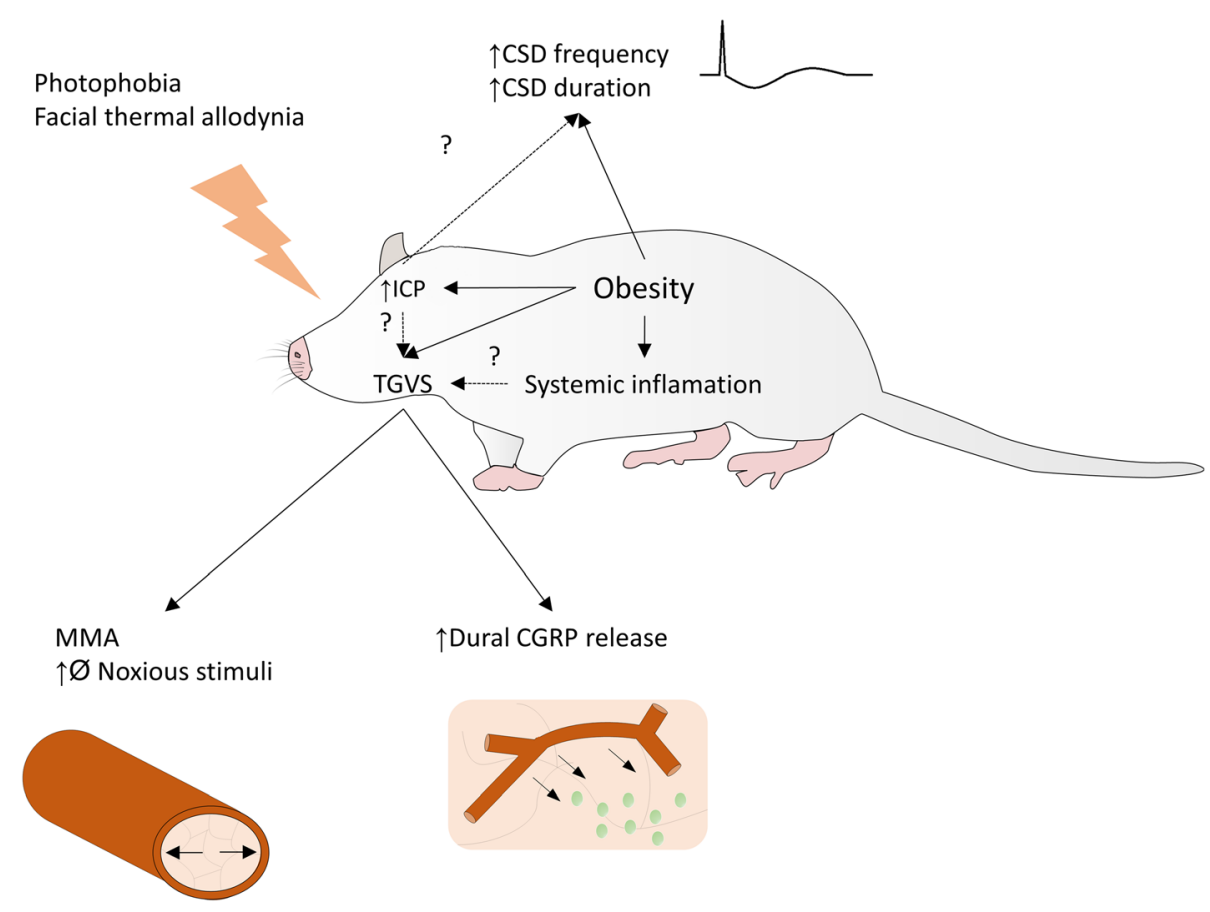

Fig. 1 The effects of obesity on headache and the trigeminovascular system. Obesity has been demonstrated to affect several aspects associated with headache. Obesity alters headache-like behavior including increasing photophobia and thermal allodynia. This is associated with a series of physiological differences including increased cortical spreading depression (CSD) frequency. The trigemino-vascular system (TGVS) also is altered with obesity where the release of calcitonin gene related peptide (CGRP) from dura middle meningeal artery (MMA) calibre ( $\varnothing$ ) display a greater response to noxious stimuli. The molecular underpinnings of these are unknown and it is unknown how obesity related systemic inflammation and intracranial pressure (ICP) alter the TGVS or headache in general

specific inflammation[13-15]. This inflammation is caused in part by the secretion of cytokines from tissue resident and infiltrating macrophages[13-15]. Given the systemic and local inflammation, and endocrine dysfunction in obesity, it is plausible that obesity is affecting the physiology of the trigeminovascular system. This is particularly important as the TG and dura mater are outside of the blood brain barrier (BBB) and thus exposed to the circulating inflammatory milieu associated with obesity [70]. Although the effects of obesity on inflammation and the endocrinology of the trigeminovascular system remain unclear, investigations into the effect of induced inflammation can provide insight into this under researched area and highlight future research avenues.

IL- $1 \beta$ is a classic pro-inflammatory cytokine and potent hyperalgesic that is raised at the serum and tissue level in both obese humans and rodents[106]. Functionally, IL- $1 \beta$ has the capacity to increase the membrane potential of small TG neurons. These nociceptive neurons demonstrated more spiking behaviour upon IL-1 $\beta$ administration through altered $\mathrm{K}^{+}$conductance[107, 108]. This suggests that the nociceptive neurons become more sensitive to stimuli, thus nociception. This study also demonstrated that peripheral inflammation induced upregulation of IL-1 $\beta$ on TG satellite glial cells and upregulation of IL-1 $\beta$ receptor on TG neurons[107]. This suggests that paracrine signalling between activated satellite glia and TG neurons could drive increased sensitivity of the TG nociceptors. The altered $\mathrm{K}^{+}$conductance in inflammation is likely directly linked to migraine pathology. The $\mathrm{K}^{\mathrm{ATP}}$ channel opener levkromakalim has been demonstrated to induce migraine in humans and migraine-like behaviour in mice, where $\mathrm{K}^{\mathrm{ATP}}$ channel opening is hypothesised to be a common pathway in migraine pain[102, 109]. Given this evidence, it is feasible that both the dura mater and TG are exposed IL-1 $\beta$ in the context of obesity. However, in the context obesity, it is unknown whether there are tissue level increases of IL-1 $\beta$ in migraine related structures.

TNF- $\alpha$ is another pro-inflammatory cytokine associated with obesity that induces hyperalgesia[110]. However, rather than being raised systemically, TNF- $\alpha$ expression in obesity is increased at the tissue level in tissues such as adipose tissue and the liver among others[111, 112]. As such, in the context of proinflammatory stimuli in obesity, it is conceivable that TNF- $\alpha$ expression is raised in the trigeminovascular system. TNF- $\alpha$ causes CGRP release in cultured TG neurons in a dose dependent manner[113]. Furthermore, 
TNF- $\alpha$ derived from macrophages has been demonstrated to increase cephalic allodynia in a rat TG trauma model, which is treatable via TNF- $\alpha$ sequestration with etanercept[114]. This demonstrates that activated macrophages have the capacity to promote nociception in the TG via TNF- $\alpha$ mediated paracrine signalling. Given that TNF- $\alpha$ expression is increased at the tissue level in obesity, particularly in tissue resident macrophages, it could be hypothesised that obesity causes an upregulation of TNF- $\alpha$ in TG macrophages and promote nociception[111, 112]. Further work is required to link inflammation and the TG in the setting of obesity.

Together, these data highlight that nociceptive cytokines known to be raised in obesity have the capacity to promote nociception at the TG. However, the expression of pro-inflammatory cytokines has yet to be assessed in an obese migraine model and thus should be a focus of future research.

\section{Intracranial pressure, obesity and headache}

In obesity, there is a growing body of evidence that increased BMI is associated with increased ICP $[115,116]$. Indeed, body fat percentage and ICP positively correlate in a mixed neurological patient cohort[117]. Furthermore, in patients with IIH it has been demonstrated that truncal adiposity positively correlates with ICP[118]. In addition, obese Zucker rats have raised ICP[119]. Together these data link adiposity to raised ICP, although the potential mechanisms underlying this are unelucidated. However, it is controversial as to whether ICP directly contributes to headache.

In IIH, weight loss and concurrent ICP reduction improves headache. Consequently, it could be suggested that deranged ICP dynamics have the potential to damage components of the trigeminovascular system causing headache or central sensitisation to pain[40]. Indeed, the structures associated with migraine are within the central nervous system, where they are under the mechanical influence of ICP and any changes in ICP could cause pain. Consistent with this, cortical tissue from IIH patients demonstrated pathological features such as astrogliosis, BBB leakage and abnormal mitochondrial morphology, which correlate with pathological ICP waveforms [120-122]. Furthermore, ICP may alter central sensitivity to pain: it has been demonstrated that ICP correlates with cutaneous allodynia and that reducing ICP causes a reduction in cutaneous allodynia in IIH patients[123, 124]. This suggests that raised ICP could lower the threshold for a migraine attack. Direct evidence of ICP influencing and potentially damaging the trigeminovascular system is lacking. Further evidence that raised ICP in the context of obesity could contribute to migraine is that one study has demonstrated that $10 \%$ of chronic migraine patients met the diagnostic criteria for IIH without papilledema (IIHWOP), where IIHWOP is otherwise considered a rare presentation of IIH[125].

Given the evidence that headache in IIH can be treated with erenumab, this suggests that either the pressure related headache in IIH is migraine, or that the IIH headache and migraine have differing pathophysiology and present in the same phenotype. Perhaps in agreement with this, a resent in vivo paper demonstrated that different rodent migraine triggers can signal through differing pathways[126].

Obesity mediated ICP increases could also alter CSD frequency: it is established that pathologically raised ICP is associated with increased CSD frequency in experimental and clinical settings[127, 128]. Indeed, obese Zucker rats have been demonstrated to have both raised ICP and increased CSDs, although it has yet to be specifically demonstrated that obesity mediated ICP increases alter CSD $[87,129]$. Thus, obesity mediated ICP increases could explain the increased MA in obese females, although the apparent reduction in aura in IIH confuses the situation. Further research is required to understand the link between raised ICP and aura.

With all of this however, it is unclear as to what degree an ICP increase may increase migraine sensitivity or directly cause a headache. This should thus be an avenue for future research. Additionally, further investigation into the ICP phenotype in both lean and obese migraine patients is important to delineate the role ICP has in migraine-like headache.

\section{Conclusions}

Migraine and obesity affect large numbers of individuals around the globe. A clear link between these diseases exists, both through epidemiology and evidenced though clinical intervention. It is apparent that obese migraine patients exhibit a more disabling phenotype than nonobese migraineurs. Furthermore, raised ICP, as present in $\mathrm{IIH}$, is associated with obesity and headache. The preclinical evidence demonstrates that obese rodents show migraine-like behaviour and have functional abnormalities in the migraine related structures. However, these pre-clinical studies fail to identify the molecular underpinnings linking obesity to migraine or $\mathrm{IIH}$, understanding of this could stimulate the development of therapeutics for obesity related migraine.

\section{Authors' contributions}

The author(s) read and approved the final manuscript.

\section{Funding}

The Candys Foundation, Lundbeck foundation (grant nr 276) and International Headache Society fellowship grant. 


\section{Declarations}

\section{Competing interests}

The authors declare that they have no competing interests.

\section{Received: 2 August 2021 Accepted: 26 September 2021} Published online: 10 October 2021

\section{References}

1. Cawley J (2015) An economy of scales: A selective review of obesity's economic causes, consequences, and solutions. J Health Econ 43:244-268

2. Flegal KM, Kit BK, Orpana $\mathrm{H}$ et al (2013) Association of all-cause mortality with overweight and obesity using standard body mass index categories: a systematic review and meta-analysis. JAMA 309:71-82

3. Guh DP, Zhang W, Bansback N et al (2009) The incidence of co-morbidities related to obesity and overweight: A systematic review and meta-analysis. BMC Public Health 9:88

4. Stovner $\sqcup$, Nichols E, Steiner TJ et al (2018) Global, regional, and national burden of migraine and tension-type headache, 1990-2016: a systematic analysis for the Global Burden of Disease Study 2016. Lancet Neurol 17:954-976

5. McLaren L (2007) Socioeconomic Status and Obesity. Epidemiol Rev 29:29-48

6. Haase $\mathrm{CL}$, Lopes S, Olsen AH et al (2021) Weight loss and risk reduction of obesity-related outcomes in 0.5 million people: evidence from a UK primary care database. Int J Obes 45:1249-1258

7. Locke AE, Kahali B, Berndt SI et al (2015) Genetic studies of body mass index yield new insights for obesity biology. Nature 518:197-206

8. Riveros-McKay F, Mistry V, Bounds R et al (2019) Genetic architecture of human thinness compared to severe obesity. PLOS Genet 15:e1007603

9. Albuquerque D, Nóbrega C, Manco L et al (2017) The contribution of genetics and environment to obesity. Br Med Bull 123:159-173

10. Sun K, Kusminski CM, Scherer PE (2011) Adipose tissue remodeling and obesity. J Clin Invest 121:2094-2101

11. Velazquez A, Apovian CM (2018) Updates on obesity pharmacotherapy. Ann N Y Acad Sci 1411:106-119

12. Buchwald H (2014) The Evolution of Metabolic/Bariatric Surgery. Obes Surg 24:1126-1135

13. Kern PA, Di Gregorio GB, Lu T et al (2003) Adiponectin expression from human adipose tissue: relation to obesity, insulin resistance, and tumor necrosis factor-alpha expression. Diabetes 52:1779-1785

14. Dandona P, Aljada A, Bandyopadhyay A (2004) Inflammation: the link between insulin resistance, obesity and diabetes. Trends Immunol 25:4-7

15. Mokdad AH, Ford ES, Bowman BA et al (2003) Prevalence of Obesity, Diabetes, and Obesity-Related Health Risk Factors, 2001. JAMA 289:76-79

16. Ashina M, Hansen JM, Do TP et al (2019) Migraine and the trigeminovascular system—40 years and counting. Lancet Neurol 18:795-804

17. Lipton RB, Stewart WF, Diamond S et al (2001) Prevalence and Burden of Migraine in the United States: Data From the American Migraine Study II. Headache J Head Face Pain 41:646-657

18. The International Classification of Headache Disorders, 3rd edition (beta version). Cephalalgia 2013; 33: 629-808

19. Lipton RB, Bigal ME, Ashina S et al (2008) Cutaneous allodynia in the migraine population. Ann Neurol 63:148-158

20. Louter MA, Bosker JE, van Oosterhout WPJ et al (2013) Cutaneous allodynia as a predictor of migraine chronification. Brain 136:3489-3496

21. Karsan N, Goadsby PJ (2018) Biological insights from the premonitory symptoms of migraine. Nat Rev Neurol 14:699-710

22. Vos T, Abajobir AA, Abate KH et al (2017) Global, regional, and national incidence, prevalence, and years lived with disability for 328 diseases and injuries for 195 countries, 1990-2016: a systematic analysis for the Global Burden of Disease Study 2016. Lancet 390:1211-1259

23. Ashina M, Migraine (2020) N Engl J Med 383:1866-1876

24. Hornby C, Mollan SP, Botfield HF et al. Metabolic Concepts in Idiopathic Intracranial Hypertension and Their Potential for Therapeutic Intervention. J Neuro-Ophthalmology 2018; 1

25. O'Reilly MW, Westgate CSJ, Hornby C et al (2019) A unique androgen excess signature in idiopathic intracranial hypertension is linked to cerebrospinal fluid dynamics. JCI Insight 4:e125348

26. Westgate CSJ, Botfield HF, Alimajstorovic Z et al. Systemic and adipocyte transcriptional and metabolic dysregulation in idiopathic intracranial hypertension. JCI Insight; 6. Epub ahead of print 24 May 2021. DOI: https:// doi.org/10.1172/jci.insight.145346
27. Peng MG, Gokoffski KK (2021) Updates on Recent Developments in Idiopathic Intracranial Hypertension. SN Compr Clin Med 3:1031-1041

28. Zouari R, Messelmani M, Derbali H et al (2021) Idiopathic Intracranial Hypertension: an Unusual Presentation of Neuromyelitis Optica-A Case Report. SN Compr Clin Med 3:1784-1788

29. Mollan SP, Aguiar M, Evison F et al. The expanding burden of Idiopathic Intracranial Hypertension. Eye 2018; 1

30. Adderley NJ, Subramanian A, Nirantharakumar K et al. Association Between Idiopathic Intracranial Hypertension and Risk of Cardiovascular Diseases in Women in the United Kingdom. JAMA Neurol. Epub ahead of print 8 July 2019. DOl: https://doi.org/10.1001/jamaneurol.2019.1812

31. Grech $\mathrm{O}$, Clouter A, Mitchell JL et al. Cognitive performance in idiopathic intracranial hypertension and relevance of intracranial pressure. Brain Commun; 3. Epub ahead of print 1 July 2021. DOl: https://doi.org/10.1093/ braincomms/fcab202

32. Yiangou A, Mitchell $J$, Nicholls $M$ et al. Obstructive sleep apnoea in women with idiopathic intracranial hypertension: a sub-study of the idiopathic intracranial hypertension weight randomised controlled trial (IIH: WT). J Neurol. Epub ahead of print 22 August 2021. DOI: https://doi.org/10.1007/ s00415-021-10700-9

33. Mulla Y, Markey KA, Woolley RL et al (2015) Headache determines quality of life in idiopathic intracranial hypertension. J Headache Pain 16:521

34. Mollan SP, Grech O, Sinclair AJ (2021) Headache attributed to idiopathic intracranial hypertension and persistent post-idiopathic intracranial hypertension headache: A narrative review. Headache J Head Face Pain 61: 808-816

35. Kleinschmidt JJ, Digre KB, Hanover R (2000) Idiopathic intracranial hypertension: relationship to depression, anxiety, and quality of life. Neurology 54:319-324

36. Witry M, Kindler C, Weller J et al (2021) The patients' perspective on the burden of idiopathic intracranial hypertension. J Headache Pain 22:67

37. Mollan SP, Hemmings K, Herd CP et al (2019) What are the research priorities for idiopathic intracranial hypertension? A priority setting partnership between patients and healthcare professionals. BMJ Open 9:e026573

38. Mollan SP, Davies B, Silver NC et al (2018) Idiopathic intracranial hypertension: consensus guidelines on management. J Neurol Neurosurg Psychiatry 89:1088-1100

39. Piper RJ, Kalyvas AV, Young AMH et al. Interventions for idiopathic intracranial hypertension. Cochrane Database Syst Rev; 2015. Epub ahead of print 7 August 2015. DOI: https://doi.org/10.1002/14651858.CD003434.pub3

40. Mollan SP, Mitchell JL, Ottridge RS et al. Effectiveness of Bariatric Surgery vs Community Weight Management Intervention for the Treatment of Idiopathic Intracranial Hypertension. JAMA Neurol. Epub ahead of print 26 April 2021. DOI: https://doi.org/10.1001/jamaneurol.2021.0659

41. Yri HM, Rönnbäck C, Wegener M et al (2014) The course of headache in idiopathic intracranial hypertension: A 12-month prospective follow-up study. Eur J Neurol 21:1458-1464

42. Yiangou A, Mitchell JL, Fisher $C$ et al. Erenumab for headaches in idiopathic intracranial hypertension: A prospective open-label evaluation. Headache Head Face Pain 2020; head.14026

43. Yiangou A, Mitchell JL, Vijay $V$ et al (2020) Calcitonin gene related peptide monoclonal antibody treats headache in patients with active idiopathic intracranial hypertension. J Headache Pain 21:116

44. Chai NC, Scher Al, Moghekar A et al (2014) Obesity and Headache: Part I - A Systematic Review of the Epidemiology of Obesity and Headache. Headache J Head Face Pain 54:219-234

45. Gelaye B, Sacco S, Brown WJ et al (2017) Body composition status and the risk of migraine: A meta-analysis. Neurology 88:1795-1804

46. Peterlin BL, Rosso AL, Rapoport AM et al (2010) Obesity and migraine: The effect of age, gender and adipose tissue distribution. Headache 50:52-62

47. Bigal ME, Lipton RB (2006) Obesity is a risk factor for transformed migraine but not chronic tension-type headache. Neurology 67:252-257

48. Bigal ME, Tsang A, Loder E et al (2007) Body mass index and episodic headaches: A population-based study. Arch Intern Med 167:1964-1970

49. Bigal ME, Liberman JN, Lipton RB (2006) Obesity and migraine: A population study. Neurology 66:545-550

50. Hershey AD, Powers SW, Nelson TD et al (2009) Obesity in the Pediatric Headache Population: A Multicenter Study. Headache J Head Face Pain 49: 170-177

51. Di Vincenzo A, Beghetto M, Vettor R et al. Effects of Surgical and Nonsurgical Weight Loss on Migraine Headache: a Systematic Review and Meta- 
Analysis. Obes Surg. Epub ahead of print 2020. DOl: https://doi.org/10.1007/ s11695-020-04429-z

52. Di Lorenzo C, Coppola G, Sirianni G et al (2015) Migraine improvement during short lasting ketogenesis: a proof-of-concept study. Eur J Neurol 22:170-177

53. Bunner AE, Agarwal U, Gonzales JF et al (2014) Nutrition intervention for migraine: a randomized crossover trial. J Headache Pain 15:69

54. Novack V, Fuchs $L$, Lantsberg $L$ et al (2011) Changes in headache frequency in premenopausal obese women with migraine after bariatric surgery: A case series. Cephalalgia 31:1336-1342

55. Sinclair AJ, Burdon MA, Nightingale PG et al (2010) Low energy diet and intracranial pressure in women with idiopathic intracranial hypertension: prospective cohort study. BMJ 341:c2701-c2701

56. Ducros A (2021) Genetics of migraine. Rev Neurol (Paris) 177:801-808

57. Chalmer MA, Esserlind A-L, Olesen J et al (2018) Polygenic risk score: use in migraine research. J Headache Pain 19:29

58. Goadsby PJ, Edvinsson L, Ekman R (1990) Vasoactive peptide release in the extracerebral circulation of humans during migraine headache. Ann Neurol 28:183-187

59. Goadsby PJ, Edvinsson L (1993) The trigeminovascular system and migraine: Studies characterizing cerebrovascular and neuropeptide changes seen in humans and cats. Ann Neurol 33:48-56

60. Bellamy JL, Cady RK, Durham PL (2006) Salivary Levels of CGRP and VIP in Rhinosinusitis and Migraine Patients. Headache J Head Face Pain 46:24-33

61. Cernuda-Morollon E, Larrosa D, Ramon C et al (2013) Interictal increase of CGRP levels in peripheral blood as a biomarker for chronic migraine. Neurology 81:1191-1196

62. Ashina H, Schytz HW, Ashina M. CGRP in Human Models of Migraine. 2018 , pp. 109-120

63. Charles A, Pozo-Rosich P (2019) Targeting calcitonin gene-related peptide: a new era in migraine therapy. Lancet 394:1765-1774

64. Hay DL, Walker CS (2017) CGRP and its receptors. Headache J Head Face Pain 57:625-636

65. Barwell J, Wheatley M, Conner AC et al (2013) The activation of the CGRP receptor. Biochem Soc Trans 41:180-184

66. Dickerson I (2013) Role of CGRP-Receptor Component Protein (RCP) in CLR/ RAMP Function. Curr Protein Pept Sci 14:407-415

67. Hay DL. CGRP Receptor Biology: Is There More Than One Receptor? 2018, pp. 13-22

68. Walker $\mathrm{CS}$, Eftekhari S, Bower RL, et al. A second trigeminal $<\mathrm{scp}>\mathrm{CGRP}</$ $\mathrm{ScP}>$ receptor: function and expression of the $\langle\mathrm{scp}>\mathrm{AMY}\langle/ \mathrm{scp}>$, receptor. Ann Clin Transl Neurol 2015; 2: 595-608.

69. Eftekhari S, Salvatore CA, Calamari A et al (2010) Differential distribution of calcitonin gene-related peptide and its receptor components in the human trigeminal ganglion. Neuroscience 169:683-696

70. Eftekhari S, Salvatore CA, Johansson S et al (2015) Localization of CGRP, CGRP receptor, PACAP and glutamate in trigeminal ganglion. Relation to the blood-brain barrier. Brain Res 1600:93-109

71. Lennerz JK, Rühle V, Ceppa EP et al (2008) Calcitonin receptor-like receptor (CLR), receptor activity-modifying protein 1 (RAMP1), and calcitonin generelated peptide (CGRP) immunoreactivity in the rat trigeminovascular system: Differences between peripheral and central CGRP receptor distribution. J Comp Neurol 507:1277-1299

72. Eftekhari S, Gaspar RC, Roberts R et al (2016) Localization of CGRP receptor components and receptor binding sites in rhesus monkey brainstem: A detailed study using in situ hybridization, immunofluorescence, and autoradiography. J Comp Neurol 524:90-118

73. Eftekhari S, Warfvinge K, Blixt FW et al (2013) Differentiation of Nerve Fibers Storing CGRP and CGRP Receptors in the Peripheral Trigeminovascular System. J Pain 14:1289-1303

74. Eftekhari S, Salvatore CA, Gaspar RC et al (2013) Localization of CGRP Receptor Components, CGRP, and Receptor Binding Sites in Human and Rhesus Cerebellar Cortex. The Cerebellum 12:937-949

75. Zelissen PMJJ, Koppeschaar HPFF, Lips CJMM et al (1991) Calcitonin generelated peptide in human obesity. Peptides 12:861-863

76. Gram DX, Hansen AJ, Wilken M et al (2005) Plasma calcitonin gene-related peptide is increased prior to obesity, and sensory nerve desensitization by capsaicin improves oral glucose tolerance in obese Zucker rats. Eur J Endocrinol 153:963-969

77. Walker CS, Li X, Whiting L et al (2010) Mice Lacking the Neuropeptide aCalcitonin Gene-Related Peptide Are Protected Against Diet-Induced Obesity. Endocrinology 151:4257-4269
78. Marics B, Peitl B, Varga A et al (2017) Diet-induced obesity alters dural CGRP release and potentiates TRPA1-mediated trigeminovascular responses. Cephalalgia 37:581-591

79. Reda TK, Geliebter A, Pi-Sunyer FX. Amylin (2002) Food Intake, and Obesity. Obes Res 10:1087-1091

80. Ghanizada H, Al-Karagholi MA, Walker CS et al (2021) Amylin Analog Pramlintide Induces Migraine-like Attacks in Patients. Ann Neurol 89:1157-1171

81. Williams DM, Nawaz A, Evans M (2020) Drug Therapy in Obesity: A Review of Current and Emerging Treatments. Diabetes Ther 11:1199-1216

82. Charles AC, Baca SM (2013) Cortical spreading depression and migraine. Nat Rev Neurol 9:637-644

83. Lauritzen M (1992) Spreading depression and migraine. Pathol Biol (Paris) 40:332-337

84. Bolay H, Vuralli D, Goadsby PJ (2019) Aura and Head pain: relationship and gaps in the translational models. J Headache Pain 20:94

85. Ayata C, Jin H, Kudo C et al (2006) Suppression of cortical spreading depression in migraine prophylaxis. Ann Neurol 59:652-661

86. Costa C, Tozzi A, Rainero I et al (2013) Cortical spreading depression as a target for anti-migraine agents. J Headache Pain 14:62

87. Kitamura E, Kanazawa N, Hamada J (2015) Hyperleptinemia increases the susceptibility of the cortex to generate cortical spreading depression. Cephalalgia 35:327-334

88. Pisanu C, Preisig M, Castelao E et al (2017) High leptin levels are associated with migraine with aura. Cephalalgia 37:435-441

89. Horev A, Wirguin I, Lantsberg L et al (2005) A high incidence of migraine with aura among morbidly obese women. Headache 45:936-938

90. Smith SR, Lovejoy JC, Greenway F et al (2001) Contributions of total body fat, abdominal subcutaneous adipose tissue compartments, and visceral adipose tissue to the metabolic complications of obesity. Metabolism 50: 425-435

91. Taksali SE, Caprio S, Dziura J et al (2008) High visceral and low abdominal subcutaneous fat stores in the obese adolescent: a determinant of an adverse metabolic phenotype. Diabetes 57:367-371

92. Mínguez-Olaondo A, Martínez-Valbuena I, Romero S et al (2020) Excess abdominal fat is associated with cutaneous allodynia in individuals with migraine: A prospective cohort study. J Headache Pain 21:9

93. Siva ZO, Uluduz D, Keskin FE et al (2018) Determinants of glucose metabolism and the role of NPY in the progression of insulin resistance in chronic migraine. Cephalalgia 38:1773-1781

94. Fava A, Pirritano D, Consoli D et al (2014) Chronic migraine in women is associated with insulin resistance: a cross-sectional study. Eur J Neurol 21: 267-272

95. Guldiken B, Guldiken S, Demir M et al (2008) Insulin Resistance and High Sensitivity C-Reactive Protein in Migraine. Can J Neurol Sci / J Can des Sci Neurol 35:448-451

96. Hellstrom L, Wahrenberg H, Hruska K et al (2000) Mechanisms behind gender differences in circulating leptin levels. J Intern Med 247:457-462

97. Mollan SP, Hoffmann J, Sinclair AJ (2019) Advances in the understanding of headache in idiopathic intracranial hypertension. Curr Opin Neurol 32:92-98

98. Rossi HL, Broadhurst KA, Luu ASK et al (2016) Abnormal trigeminal sensory processing in obese mice 157:235-246

99. Rossi HL, Lara O, Recober A (2016) Female sex and obesity increase photophobic behavior in mice. Neuroscience 331:99-108

100. Rossi HL, Luu AKS, Kothari SD et al (2013) Effects of diet-induced obesity on motivation and pain behavior in an operant assay. Neuroscience 235:87-95

101. Rossi HL, Raj NR, Marquez de Prado B et al (2019) Trigeminal Pain Responses in Obese ob/ob Mice Are Modality-Specific. Neuroscience 415: 121-134

102. Christensen SL, Munro G, Petersen S et al (2020) ATP sensitive potassium (K ATP) channel inhibition: A promising new drug target for migraine. Cephalalgia 40:650-664

103. Cheng J-K, Ji R-R (2008) Intracellular Signaling in Primary Sensory Neurons and Persistent Pain. Neurochem Res 33:1970-1978

104. Marics B, Peitl B, Pázmándi K et al (2017) Diet-Induced Obesity Enhances TRPV1-Mediated Neurovascular Reactions in the Dura Mater. Headache 57: $441-454$

105. Rossi HL, Luu AKSS, Devilbiss JL et al (2013) Obesity increases nociceptive activation of the trigeminal system. Eur J Pain (United Kingdom) 17:649-653

106. Ferreira SH, Lorenzetti BB, Bristow AF et al (1988) Interleukin-1 $\beta$ as a potent hyperalgesic agent antagonized by a tripeptide analogue. Nature 334:698-700 
107. Takeda M, Tanimoto T, Kadoi J et al (2007) Enhanced excitability of nociceptive trigeminal ganglion neurons by satellite glial cytokine following peripheral inflammation. Pain 129:155-166

108. Takeda M, Kitagawa J, Takahashi M et al (2008) Activation of interleukin-1 $\beta$ receptor suppresses the voltage-gated potassium currents in the smalldiameter trigeminal ganglion neurons following peripheral inflammation. Pain 139:594-602

109. Al-Karagholi MA-M, Hansen JM, Guo S et al (2019) Opening of ATP-sensitive potassium channels causes migraine attacks: a new target for the treatment of migraine. Brain 142:2644-2654

110. Cunha FQ, Poole S, Lorenzetti BB et al (1992) The pivotal role of tumour necrosis factor $\mathrm{a}$ in the development of inflammatory hyperalgesia. $\mathrm{Br} \mathrm{J}$ Pharmacol 107:660-664

111. Hotamisligil GS, Arner P, Caro JF et al (1995) Increased adipose tissue expression of tumor necrosis factor-alpha in human obesity and insulin resistance. J Clin Invest 95:2409-2415

112. Hotamisligil GS, Peraldi P, Budavari A et al (1996) IRS-1-mediated inhibition of insulin receptor tyrosine kinase activity in TNF-alpha- and obesityinduced insulin resistance. Science 271:665-668

113. Bowen EJ, Schmidt TW, Firm CS et al (2006) Tumor necrosis factor-alpha stimulation of calcitonin gene-related peptide expression and secretion from rat trigeminal ganglion neurons. J Neurochem 96:65-77

114. Koizumi M, Asano S, Furukawa A et al. P2 $\times 3$ receptor upregulation in trigeminal ganglion neurons through TNFa production in macrophages contributes to trigeminal neuropathic pain in rats. J Headache Pain; 22. Epub ahead of print 26 December 2021. DOl: https://doi.org/10.1186/s101 94-021-01244-4

115. Berdahl JP, Fleischman D, Zaydlarova J et al (2012) Body Mass Index Has a Linear Relationship with Cerebrospinal Fluid Pressure. Investig Opthalmology Vis Sci 53:1422

116. Ren R, Wang N, Zhang X et al (2012) Cerebrospinal fluid pressure correlated with body mass index. Graefe's Arch Clin Exp Ophthalmol 250:445-446

117. Wakerley BR, Warner R, Cole M et al (2020) Cerebrospinal fluid opening pressure: The effect of body mass index and body composition. Clin Neurol Neurosurg 188:105597

118. Hornby C, Botfield HF, O'Reilly MW et al (2018) Evaluating the Fat Distribution in Idiopathic Intracranial Hypertension Using Dual-Energy X-ray Absorptiometry Scanning. Neuro-Ophthalmology 42:99-104

119. Uldall M, Bhatt DK, Kruuse C et al (2017) Choroid plexus aquaporin 1 and intracranial pressure are increased in obese rats: Towards an idiopathic intracranial hypertension model? Int J Obes 41:1141-1147

120. Hasan-Olive MM, Hansson H-A, Enger R et al. Blood-Brain Barrier Dysfunction in Idiopathic Intracranial Hypertension. J Neuropathol Exp Neurol. Epub ahead of print 4 July 2019. DOl: https://doi.org/10.1093/jnen/ nlz063

121. Eide PK, Hasan-Olive MM, Hansson $\mathrm{H}$ et al. Increased occurrence of pathological mitochondria in astrocytic perivascular endfoot processes and neurons of idiopathic intracranial hypertension. J Neurosci Res 2020; jnr. 24743

122. Eide PK, Eidsvaag VA, Nagelhus EA et al (2016) Cortical astrogliosis and increased perivascular aquaporin-4 in idiopathic intracranial hypertension. Brain Res 1644:161-175

123. Ekizoglu E, Baykan B, Orhan EK et al (2012) The analysis of allodynia in patients with idiopathic intracranial hypertension. Cephalalgia 32:1049-1058

124. Mollan S, Wakerley B, Alimajstorovic Z, Mitchell J, Ottridge R, Yiangou A, Thaller MJ, Grech O, Lavery G, Brock KSA. Intracranial Pressure Directly Predicts Headache Morbidity in Idiopathic Intracranial Hypertension. Res Sq. DOI: https://doi.org/10.21203/rs.3.rs-479747/v1

125. Vieira D, Masruha M, Gonçalves A et al (2008) Idiopathic Intracranial Hypertension With and Without Papilloedema in a Consecutive Series of Patients With Chronic Migraine. Cephalalgia 28:609-613

126. Christensen SL, Rasmussen RH, Ernstsen C et al. CGRP-dependent signalling pathways involved in mouse models of GTN- cilostazol- and levcromakaliminduced migraine. Cephalalgia 2021; 033310242110388

127. Rogatsky GG, Sonn J, Kamenir Y et al (2003) Relationship between Intracranial Pressure and Cortical Spreading Depression following Fluid Percussion Brain Injury in Rats. J Neurotrauma 20:1315-1325

128. Lauritzen M, Dreier JP, Fabricius M et al (2011) Clinical relevance of cortical spreading depression in neurological disorders: migraine, malignant stroke, subarachnoid and intracranial hemorrhage, and traumatic brain injury. J Cereb Blood Flow Metab 31:17-35
129. Uldall M, Bhatt DK, Kruuse $C$ et al (2017) Choroid plexus aquaporin 1 and intracranial pressure are increased in obese rats: towards an idiopathic intracranial hypertension model? Int J Obes 41:1141-1147

\section{Publisher's Note}

Springer Nature remains neutral with regard to jurisdictional claims in published maps and institutional affiliations.
Ready to submit your research? Choose BMC and benefit from:

- fast, convenient online submission

- thorough peer review by experienced researchers in your field

- rapid publication on acceptance

- support for research data, including large and complex data types

- gold Open Access which fosters wider collaboration and increased citations

- maximum visibility for your research: over $100 \mathrm{M}$ website views per year

At BMC, research is always in progress.

Learn more biomedcentral.com/submissions 